\title{
Effect of high-temperature extracted plant material fume against southern cowpea weevil (Callosobruchus chinensis L.) (Coleoptera: Bruchidae) as a non-chemical novel fumigation technique
}

\author{
B. D. Rohitha Prasantha* (D)
}

\begin{abstract}
Background: Fumes from high-temperature heated plant leaves containing volatile phytochemicals generated from Lantana camara, Cinnamomum zeylanicum, Azadirachta indica and Ocimum sanctum were tested for their insecticidal activity against adult southern cowpea weevil (Callosobruchus chinensis L.) and their $F_{1}$ progeny production/ emergence. Volatile phytochemicals containing fume was generated using a flameless dry heat extraction method similar to pyrolysis combustion without air supplement at $180 \pm 5^{\circ} \mathrm{C}$. Insect mortalities were assessed up to $72 \mathrm{~h}$ after exposure to the different treatments of fumigation by plant-fume and control.

Results: All volatile plant-fume samples contained average of $16.3 \pm 1.5 \% \mathrm{O}_{2}$ and $5.8 \pm 0.5 \% \mathrm{CO}_{2}$ in the test jars. The $\mathrm{F}_{1}$ progeny emergence was estimated 30 days after treatment. After $36 \mathrm{~h}$ of exposure, L. camara showed the highest toxicity against $C$. chinensis, followed by $O$. sanctum, $A$. indica and C. zeylanicum, with $L T_{50}$ values of 7.3, 9.4, 14.7 and $20.6 \mathrm{~h}$, respectively. The volatile phytochemical containing plant-fume generated by A. indica and C. zeylanicum produced $\mathrm{LT}_{99}$ values that were not significantly different $(P>0.05)$ from each other. The $F_{1}$ adult emergence from treated mungbean (Vigna radiata L.) samples was significantly inhibited by L. camara and A. indica volatile plant-fume compared to C. zeylanicum fume. However, plant-fume generated from all four plants exhibited effective direct toxicity and $F_{1}$ progeny inhibition of more than $86 \%$.
\end{abstract}

Conclusion: From the study, it can be concluded that volatile plant-fume treatment was highly lethal to $C$. chinensis and significantly reduced $F_{1}$ progeny emergence. Therefore, phytochemicals obtained from thermal extraction technique can be used as an alternative technique to chemical fumigation of stored mungbean.

Keywords: Callosobruchus chinensis, Cowpea weevil, Fumigation, Mungbean, Phytochemical, Volatile plant-fume

\section{Background}

Grain legumes are an important source of dietary protein for low-income earners of many regions in Asia and Africa. About $40 \%$ of grain legumes harvested in

*Correspondence: rop_bd@yahoo.com; bdrp@pdn.ac.lk Department of Food Science \& Technology, Faculty of Agriculture, University of Peradeniya, Peradeniya 20400, Sri Lanka
Sri Lanka are stored by farmers for personal consumption over a period of 3-6 months [1]. Mungbean (Vigna radiata (L.) Wilczek) is the green grain legume most commonly stored in poly-sack bags after harvesting, which similar in many Asian and African countries. This type of on-farm storage results in significant postharvest losses of mungbean due to heavy insect and fungal damage. According to previous study [2], grain damage in Sri 
Lanka could be high as $60 \%$ after 6 months of storage in poly-bags.

Stored grain legumes are susceptible to damage by stored product insects such as Southern cowpea weevil (Callosobruchus chinensis L.) and cowpea weevil (Callosobruchus maculatus F.) (Coleoptera: Bruchidae) throughout the year. Infestation of grain legumes including mungbean starts in the farmers' field [3], and this infestation is carried into storage, resulting in further infestation and deterioration of the stored mungbean. The population of insects develop in the grains at a rapid rate under favourable tropical climatic conditions such as high humidity and temperature [4]. In order to protect mungbean from infestation from beetles, farmers apply hazardous insecticides to their crop soon after harvesting and several times during storage. Phosphine fumigation is the most common technique used for controlling stored product insects in large commercial granaries. However, it is not recommended for farm level application due to safety concerns. Also, the development of resistance to chemical fumigation has become a major problem for control of stored product pest [5].

As an alternative to fumigation, farmers traditionally use many dried plant materials and their generated smoke after burning the different plant materials to control stored product insects inside the grain storage [6]. In traditional system plant materials is burnt using redhot coconut shell charcoal. Botanical fumigants have long been known as organic alternatives to synthetic chemical insecticides for pest management in stored products [7]. Although the efficacy and exact mode of action of such methods are not well known, fumigants from plant materials can either be used as protectants or disinfestation methods for stored product pests $[8,9]$. This type of smoke or fumes may contain many volatile phytochemicals gasses and other volatile organic compounds (VOCs), which may be released during partial burning/heating or pyrolysis burning of plant materials [10] and some gasses. Practical application of phytochemical extracts (i.e. essential oils or other volatile extracts) into bulk-stored grains may not be an easy task due to their extraction process, nature of volatility and diffusivity. However, fumigation, smoking and fogging are relatively simple methods to apply volatile chemical pesticides in bulk grain storage facilities. Stored product pest management heavily relies on chemical pesticides and chemical fumigation, which cause significant impact on health and environment. Today, considerable amount of grains, nuts, herbs and are produced through organic agriculture, but synthetic pesticides or chemical fumigation must not be applied to preserve stored foods according to the strict regulation of organic produces. Therefore, investigation of traditional knowledge of plant material derived phytochemical fume/smoke (volatile plant-fume) is important to develop alternative nonchemical, but natural plant material-based fumigation techniques to protect the stored grains. In traditional system-generated smoke may not be an effective and environmentally sound method because smoke may contain a high amount of carbon monoxide $(\mathrm{CO})$, carbon dioxide $\left(\mathrm{CO}_{2}\right)$, methane $\left(\mathrm{CH}_{4}\right)$, hydrogen $\left(\mathrm{H}_{2}\right)$, other gasses and water vapour $\left(\mathrm{H}_{2} \mathrm{O}\right)$ rather than phytochemicals. Therefore, a modification of traditional knowledge is necessary to develop the novel fumigation method.

The objective of this study was to evaluate the efficacy of organic phytochemical containing volatile plant-fume extracted under high-temperature heating as a new fumigation method for control of $C$. chinensis infested mungbean. High-temperature heating may be similar to the "pyrolysis" of plant materials [6, 7].

\section{Methods \\ Insect culture}

A sample of newly harvested mungbean (variety MI-6) was obtained from the Department of Agriculture, Sri Lanka. Prior to the experiment, grain samples were stored under frozen conditions $\left(-18{ }^{\circ} \mathrm{C}\right)$ for $2-3$ weeks to destroy any hidden infestations of insects. Adult $C$. chinensis insects were obtained from a culture maintained on mungbean at the Department of Agricultural Biology, Faculty of Agriculture, University of Peradeniya, Sri Lanka for this study.

\section{Plant-fume generation}

Plant materials such as Lantana camara (L.), Ocimum sanctum (L.) and Azadirachta indica (L.) were obtained from Anuradhapura area, North Central province and Cinnamomum zeylanicum (L.) was obtained from Southern province of Sri Lanka. Leaves from matured plants of L. camara (L.), C. zeylanicum (L.), A. indica (L.) and areal part of the O. sanctum (L.) plants were collected from farmers' fields at the respective area and then brought to the research laboratory of the Department of Food Science and Technology, Faculty of Agriculture, University of Peradeniya, Sri Lanka. Leaves and shoots were separated from the woody branches of the plant material. All the samples were separately air dried at room temperature $\left(32{ }^{\circ} \mathrm{C}\right)$ for about 4 weeks.

Air-dried leaf samples were manually crushed and refrigerated prior to the study. Plant leaves were directly dry heated without air supplement (similar to pyrolysis) in an airtight $500-\mathrm{mL}$ tween-neck round-bottom flask (Fig. 1). The flask containing plant leaf sample was heated using laboratory electric heating mantle unit (AREC, VELP-Scientifica, Italy) at $180 \pm 5{ }^{\circ} \mathrm{C}$. Volatile plant-fume generated in this manner was collected from 
the top of the flask and sent through a 500-mL gas-wash bottle containing glass-wool and silica gel layers to filter ashes in the fume and reduce the moisture in the fume, respectively. The generated fume was sent into a 2-L glass vacuum desiccator through a copper tube. The desiccator was used as a "test jar" for fumigation bioassays.

The test jar was connected to the gas-wash bottle and the fume was drawn into the jar through a suction pump. Inside the jar, temperature and relative humidity (RH) were monitored using a data logger (EL-USB-2-LCD, Lascar Electronics, Hong Kong). A beaker of $200 \mathrm{~mL}$ of saturated sodium chloride $(\mathrm{NaCl})$ solution was kept inside the test jar to maintain the equilibrium relative humidity around $75 \%$. The internal atmosphere of the test jar was agitated with a magnetic stirrer. Oxygen and carbon dioxide concentrations of the inside the test jar were monitored using a gas analyser (Quantek model902D, Quantek Instruments, Inc, USA) at the input port. The glass-wool layer was replaced after each replicate due to accumulated fine solids partials and tar.

\section{Fumigation bioassay}

Fifty mixed sex 1- to 2-day-old adult C. chinensis and $250 \mathrm{~g}$ of mungbean were enclosed in a cage $\left(\approx 325 \mathrm{~cm}^{3}\right)$ of fine steel gauze mesh (\#40 mesh) and placed inside the airtight bioassay test jar (2-L vacuum desiccator). Preheated flask $\left(180^{\circ} \mathrm{C}\right)$ was loaded with approximately $30 \mathrm{~g}$ crushed dry leaf samples to generate/release the volatile plant-fume for mungbean fumigation. Prior to the bioassay, the plant sample was generated over $10 \mathrm{~min}$ of heating at $180 \pm 5{ }^{\circ} \mathrm{C}$ (similar to the pyrolysis burning/dry heating) inside the airtight flask (closing D and J in Fig. 1) and then volatile plant-fume was sent into the bioassay test jar after opening the valves J (Fig. 1) while operating the suction pump $(1.5 \mathrm{l} / \mathrm{min})$ by about $2-3 \mathrm{~min}$. The temperature of the fume was brought down to near room temperature $\left(\approx 38{ }^{\circ} \mathrm{C}\right)$ passing through the copper tube with a moist cotton wool layer ( $\mathrm{H}$ in Fig. 1) wrapped around the tube ( $\mathrm{G}$ in Fig. 1). The cotton wool layer was regularly moistened with flowing ambient water (I in Fig. 1). Accumulated volatile plant-fume inside the airtight test jar was agitated (O in Fig. 1) using a magnetic stirrer after closing valves "I" in the experimental setup. Treated sample jars were maintained at room temperature $\left(30 \pm 1{ }^{\circ} \mathrm{C}\right)$ prior to estimation of mortality. Insect mortalities were determined $0,2,6,10,18,24,36,48$ and $72 \mathrm{~h}$ after treatments and the samples were discarded after the mortality assessment (as a destructive method). Adults were considered dead if appendages did not move when prodded with an insect pin. Control treatments consisted of heated and filtered air pump through the experimental setup without any fume. All bioassays were repeated in triplicate.

\section{Fecundity}

Uninfested mungbean samples $(250 \mathrm{~g})$ were enclosed in a fine steel gauze cage similar to previous the bioassays setup. Each mungbean sample was treated/fumigated with the respective volatile plant-fume separately prior to the experiment. The volatile plant-fume-treated sample was stored about $4 \mathrm{~h}$ in the bioassay test jar at $30 \pm 1{ }^{\circ} \mathrm{C}$ to settle down the plant-fume. A group of 50 mixed sex (1-2 days old) $C$. chinensis was released into the

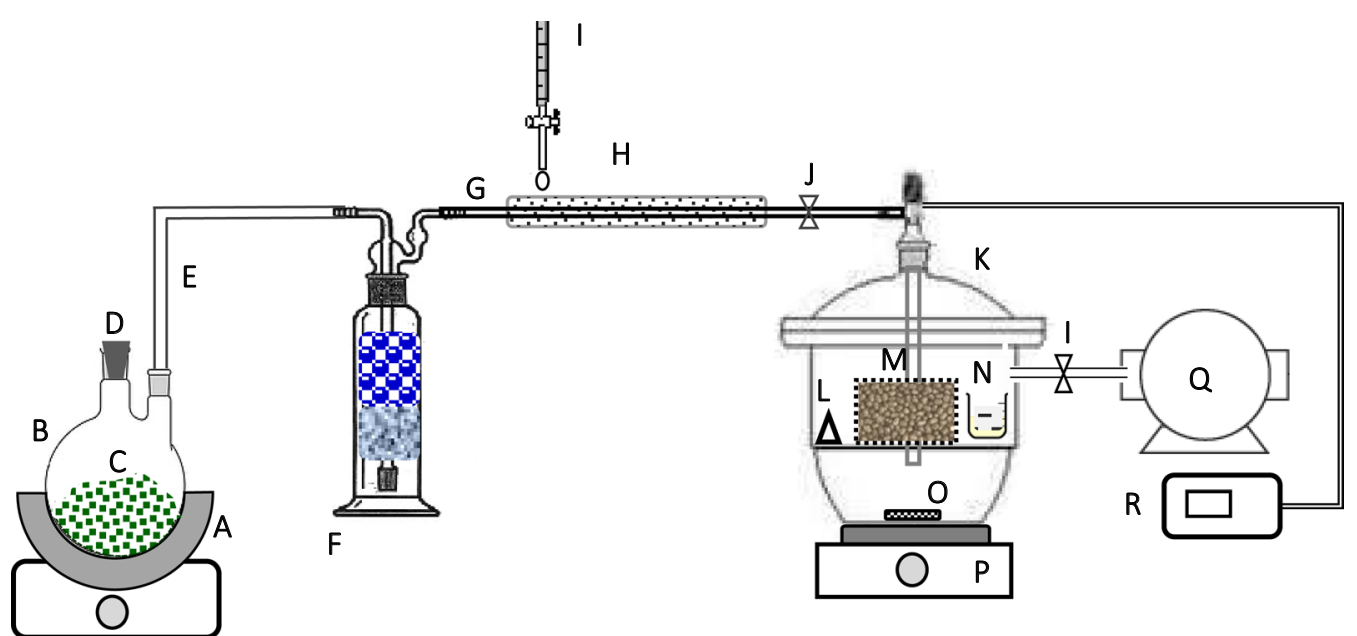

Fig. 1 Laboratory setup of volatile plant-fume generation from dry heat extraction of plant leaves (A) electric heating mantle, (B) tween-neck round-bottom flask, (C) dry plant leaves, (D) stopper, (E) stainless steel tubes, (F) gas-wash bottle with glass-wool and silica gel layers, (G) copper tubes, (H) moist cotton wool layers, (I) flowing ambient water, (J) one-way stop valves, $(K)$ volatile phytochemical fume collecting test glass jar (bioassay jar), (L) Temperature-RH data logger, $(\mathrm{M})$ mungbean sample in steel mesh cage, $(\mathrm{N})$ saturated $\mathrm{NaCl},(\mathrm{O})$ magnet, $(\mathrm{P})$ magnetic stirrer, $(\mathrm{Q})$ suction pump, (R) gas analyser 
respective plant-fume-treated mungbean samples to test $\mathrm{F}_{1}$ progeny production after 30 days. The samples were kept in an aerated glass jars under at ambient conditions $\left(30 \pm 2{ }^{\circ} \mathrm{C}\right.$ and $\mathrm{RH} 74 \pm 3 \%$ ). Similarly, control samples of $250 \mathrm{~g}$ of mungbean were also treated with air only and then infested with 50 unsexed weevils. All samples were held in a 1-L aerated glass jar and stored under ambient room conditions. The $\mathrm{F}_{1}$ progeny production/emergence was estimated 30 days after plant-fume-treated and control samples. All samples were kept for 2 days under $-10{ }^{\circ} \mathrm{C}$ to kill any emerged weevils, which were removed by sieving. The $F_{1}$ progeny emergence inhibition percentage (PI\%) was calculated by the following simple Eq. (1). All fecundity tests were conducted in triplicate with 3 parental cohorts:

$$
\mathrm{PI} \%=1-\frac{N_{\mathrm{T}}}{N_{\mathrm{C}}} \times 100
$$

where PI\% is the progeny emergence inhibition percentage; $N_{\mathrm{T}}$ is the number of insects in treatment and $N_{\mathrm{c}}$ is the number of insects in control sample.

\section{Statistical analysis}

All treatments and controls were replicated 3 times. Percentage mortality data of weevils were first corrected using Abbott's corrections. The corrected data were then subjected to Probit analysis by using the following nonlinear logistic dose response equation [11]. The SASNLIN least square estimation method (SAS 9.1, SAS Institute) was used to fit the experimental data to an Eq. (2). The adjusted regression coefficient $\left(r_{\text {adj }}^{2}\right)$, fit standard error (FSE) and F statistic values as goodnessof-fit statistics were used to evaluate the curve fitting to mortality data. The $\mathrm{LT}_{50}, \mathrm{LT}_{99}$ and $\mathrm{F}_{1}$ progeny emergence values were analysed using two-way repeated analysis of variance (ANOVA) and the least significant difference (LSD) test was used to separate the means at 95\% confidence interval $(P<0.05)$ :

$$
Y=q+\frac{a}{1+\left(\frac{t}{b}\right)^{c}}
$$

where $Y$ is the insect mortality (\%) at given exposure time, $t$ is the exposure time (h), $q$ is the lowest efficiency of mortality (\%) when $t=>0$ assuming $q=0, a=$ highest efficiency of mortality (\%) when $t=>\infty$ at $a=100 \%$ mortality, $b$ is the model constant of curve transition and $c$ the slope factor of the curves.

\section{Results}

Immediately after fumigation treatments average oxygen $\left(\mathrm{O}_{2}\right)$ in the test jars was dropped to $16.3 \pm 1.5 \%$ and $\mathrm{CO}_{2}$ content in the test jar was increased to $5.8 \pm 0.5 \%$ (Fig. 2).
The temperature inside the test jar was around $37 \pm 2{ }^{\circ} \mathrm{C}$. Although high $\mathrm{CO}_{2}$ and low $\mathrm{O}_{2}$ contents were detected in the test jar, there was no significant difference $(P>0.05)$ of $\mathrm{CO}_{2}$ and $\mathrm{O}_{2}$ contents (\%) among the four plant-fume samples. The highest and the lowest $\mathrm{CO}_{2}$ contents of $6.4 \pm 1.8 \%$ and $5.4 \pm 1.1 \%$ were observed in C. zeylanicum and $O$. sanctum plant-fume-treated jars, respectively. Control samples also showed slightly reduced $\mathrm{O}_{2}$ content during treatments, but atmospheric $\mathrm{O}_{2}$ level was regained immediately after treatment. Among the generated plantfume samples, the lowest $\mathrm{O}_{2}$ content of $14.2 \pm 1.4 \%$ were detected in C. zeylanicum fume which was significantly $(P<0.05)$ lower than the $\mathrm{O}_{2}$ content found in L. camara fume.

The effect of four different volatile phytochemical containing plant-fume fumigation treatments on adult $C$. chinensis mortality over time is shown in Fig. 3 . The results of this study showed that volatile phytochemical

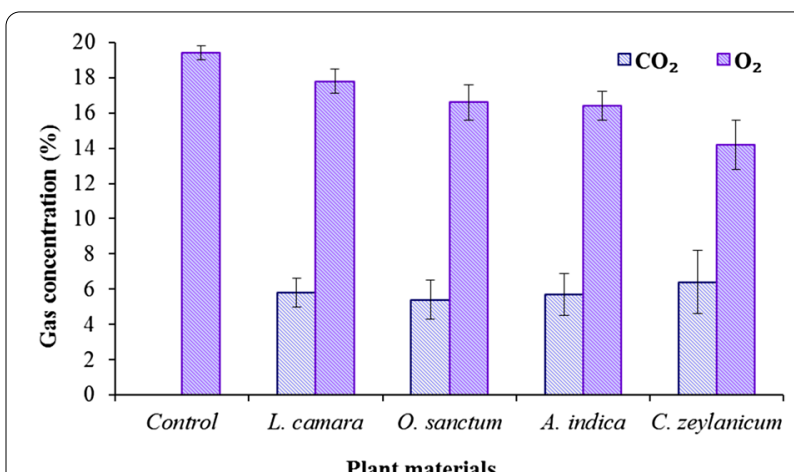

Fig. 2 The percentage content of $\mathrm{CO}_{2}$ and $\mathrm{O}_{2}$ yield in the test jar after the high-temperature dry heat extraction of volatiles from four different types of plant leaves (mean \pm SD)

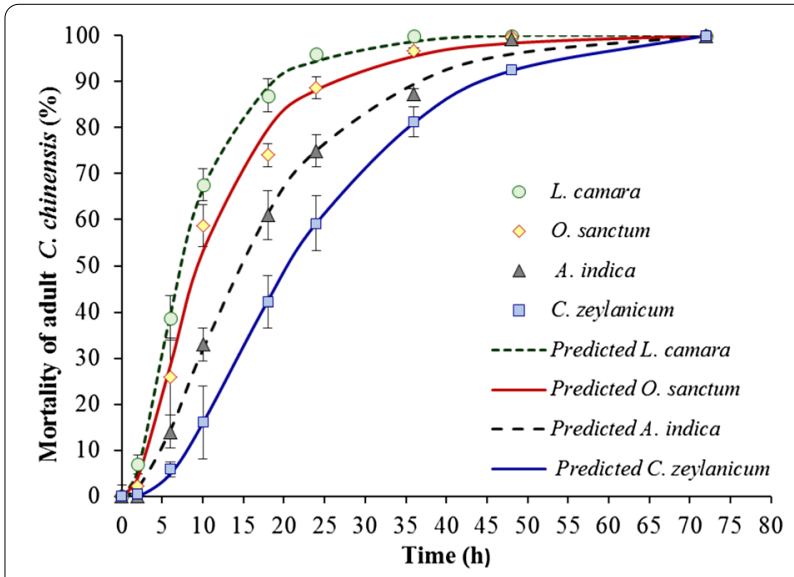

Fig. 3 Predicated and observed mean percentages of C. chinensis mortality (mean \pm SD) exposure to volatile plant-fume generated by four different types of plant leaves 
contained in plant-fume obtained from all the tested plant leaves was toxic to $C$. chinensis. Among the tested plant-fume, L. camara showed highest efficacy followed by $O$. sanctum, A. indica and C. zeylanicum. Plant-fume of L. camara resulted in $100 \%$ mortality within $36 \mathrm{~h}$ after treatments, while O. sanctum, $A$. indica and C. zeylanicum treatments showed mortalities of $96.67 \%$, 87.33\% and $80.33 \%$, respectively. The plant-fume treatments of O. sanctum caused $100 \%$ mortality at $48 \mathrm{~h}$ after treatment and fume from A. indica and C. zeylanicum showed 100\% mortality at $72 \mathrm{~h}$ after fumigation treatment. Weevil mortality was $58 \%$ and $68 \%$ after $10 \mathrm{~h}$ of exposure to fume generated from L. camara and O. sanctum leaves, respectively. Toxicity of volatile containing plant-fume treatments with $A$. indica was comparatively slow, but $>60 \%$ mortality was achieved at $18 \mathrm{~h}$ after treatment. Volatile plant-fume generated from C. zeylanicum took the longest time to attain mortality, taking nearly $24 \mathrm{~h}$ to obtain $60 \%$ mortality after treatment. The adjusted $r_{\text {adj }}^{2}$ and the F statistics values in the range of $0.98-0.99$ and 527.03-1321.34 between the observed and predicted mortality data of $C$. chinensis, respectively. Therefore, logistic dose response Eq. (2) is well fitted to the mortality data of weevils in responds to four different plantfume fumigation treatments (Table 1).

The ANOVA values $\mathrm{LT}_{50}$ and $\mathrm{LT}_{99}$ showed that there was significant difference $\left(\mathrm{LT}_{50}: F_{3,11}=36.53, P<0.05\right.$; $\left.\mathrm{LT}_{99}: F_{3,11}=97.8, P<0.05\right)$ in response of $C$. chinensis to the four plant-fume treatments (Table 2). The fume generated by $L$. camara showed the highest toxicity with significantly lower $\operatorname{LT}_{50}\left(7.3 \pm 0.6 \mathrm{~h} ; F_{3,11}=36.53, P<0.05\right)$ and $\mathrm{LT}_{99}\left(37.6 \pm 0.8 \mathrm{~h} ; F_{3,11}=97.8, P<0.05\right)$ when compared to the other three plant-fume samples. The highest $\mathrm{LT}_{50}\left(20.6 \pm 0.7 \mathrm{~h} ; F_{3,11}=36.53, P<0.05\right)$ and $\mathrm{LT}_{99}$ $\left(61.2 \pm 2.5 \mathrm{~h} ; F_{3,11}=97.8, P<0.05\right)$ was shown by fume of C. zeylanicum. According to $\mathrm{LT}_{50}$ and $\mathrm{LT}_{99}$ values, $L$. camara fume was about 2 and $1.5 \times$ more toxic than $A$. indica and C. zeylanicum fume, respectively. There was no significant difference $(P>0.05)$ between $\mathrm{LT}_{99}$ values of $A$. indica and C. zeylanicum, although A. indica $\mathrm{LT}_{50}$ values were significantly lower than those of C. zeylanicum.

Similar to adult mortality, all volatile phytochemical plant-fume treatments significantly reduced $\left(F_{3,11}=30.65, P<0.05\right) F_{1}$ progeny emergence (Fig. 4) of $C$. chinensis when compared to the control. Control samples had mean $F_{1}$ progeny of $1858 \pm 354$. The $\mathrm{F}_{1}$ progeny emergence from $O$. sanctum and C. zeylanicum fume treatments $(147.7 \pm 34.6$ and $260.7 \pm 51$, respectively) were significantly higher $\left(F_{3,11}=30.65\right.$, $P<0.05)$ than that from $L$. camara and A. indica treatments (50 \pm 13.6 and $76 \pm 11.5$, respectively). Highest and lowest $F_{1}$ progeny emergence inhibitions were obtained from plant-fume derived from $L$. camara (98\%) and C. zeylanicum (87\%), respectively (Table 2), but the difference was only $11 \%$ between two plantfume types. In spite of lethality-time relation showing significant differences among the different plant material fumes, $F_{1}$ progeny emergence inhibition percentage indicated that all the tested plant material fumes were effectively reduced the $\mathrm{F}_{1}$ progeny.

\section{Discussion}

A large number of phytochemicals extracted from different plant species have already been tested and identified for insect toxicity, as potential fumigants for stored grain legumes [12-14]. Volatile compounds of plant extracts contain many bioactive molecules including monoterpenes, sesquiterpenes and phenyl propanoids, which are the dominant constituents of essential oils. These compounds can act as pesticides, insect repellents, feeding deterrents, antimicrobials and antioxidants $[7,15,16]$.

Pyrolysis or high-temperature dry heat extraction is a thermal decomposition method of organic materials at high temperature under a low $\mathrm{O}_{2}$ environment or in a vacuum, which involves the irreversible change of chemical composition [17]. During the pyrolysis process, plant

Table 1 Estimated model fitting statistics and parameters of the non-linear logistic dose response equation used to estimate the lethal time response of $C$. chinensis

\begin{tabular}{|c|c|c|c|c|c|c|}
\hline \multirow[t]{2}{*}{ Plant species } & \multicolumn{3}{|c|}{ Goodness-of-fit statistics } & \multicolumn{3}{|c|}{ Parameters $( \pm 95 \% \mathrm{Cl})^{\S}$} \\
\hline & $r_{\mathrm{adj}}^{2}$ & $\mathrm{FSE}^{\dagger}$ & $\mathrm{F}^{\neq}$ & $\bar{a}$ & $b$ & $c$ \\
\hline Lantana camara & 0.99 & 2.47 & 950.27 & $100.68( \pm 3.6)$ & $7.35( \pm 0.5)$ & $-2.42( \pm 0.41)$ \\
\hline Ocimum sanctum & 0.99 & 2.94 & 844.16 & $109.2( \pm 10.86)$ & $22.24( \pm 3.07)$ & $-2.24( \pm 0.46)$ \\
\hline Azadirachta indica & 0.99 & 2.30 & 1321.4 & $105.25( \pm 6.37)$ & $15.43( \pm 1.57)$ & $-2.07( \pm 0.3)$ \\
\hline Cinnamomum zeylanicum & 0.98 & 3.46 & 527.03 & $101.44( \pm 6.67)$ & $9.57( \pm 1.18)$ & $-2.104( \pm 0.5)$ \\
\hline
\end{tabular}

\footnotetext{
* Adjusted regression coefficient

${ }^{\dagger}$ Fit standard error

₹ $F$ statistic values

§ $95 \%$ confidence interval
} 
Table 2 The lethal time response $\left( \pm S E\right.$ ) and inhibition of $F_{1}$ progeny emergence $( \pm S E)$ of $C$. chinensis to plant-fume derived from four different plant leaves

\begin{tabular}{|c|c|c|c|}
\hline Plant species & $\mathrm{LT}_{50}( \pm \mathrm{SE})(\mathrm{h})$ & $\mathrm{LT}_{99}( \pm \mathrm{SE})(\mathrm{h})$ & $\begin{array}{l}\text { Percent progeny } \\
\text { inhibition } \\
\text { ( } \pm \text { SE\%) }\end{array}$ \\
\hline Lantana camara & $7.30( \pm 0.57)^{\mathrm{a}}$ & $37.60( \pm 0.83)^{\mathrm{a}}$ & $98.37( \pm 0.45)^{\mathrm{a}}$ \\
\hline Ocimum sanctum & $9.41( \pm 0.46)^{b}$ & $52.87( \pm 1.1)^{b}$ & $93.13( \pm 1.1)^{b}$ \\
\hline Azadirachta indica & $14.74( \pm 0.42)^{c}$ & $58.41( \pm 2.1)^{c}$ & $97.00( \pm 0.41)^{\mathrm{a}}$ \\
\hline Cinnamomum zeylanicum & $20.60( \pm 0.70)^{d}$ & $61.23( \pm 2.52)^{c}$ & $87.04( \pm 1.6)^{c}$ \\
\hline
\end{tabular}

Means in a column followed by the same letters are not significantly different $(P>0.05)$ by LSD

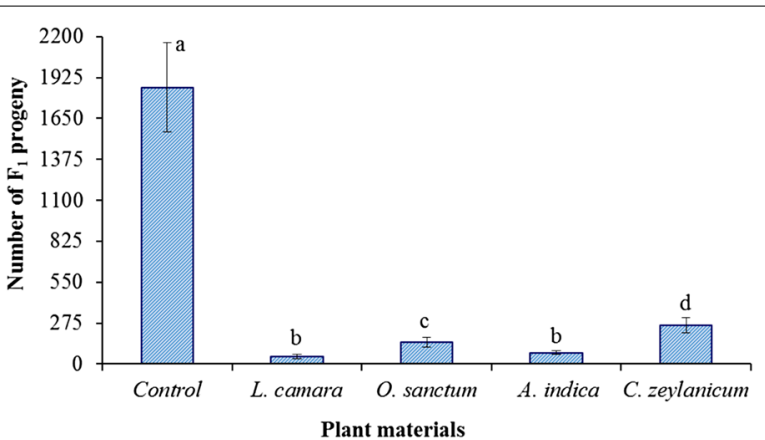

Fig. 4 Effect of volatile plant-fume derived from leaves of four plant species on the $F_{1}$ progeny emergence of $C$. chinensis (mean $\pm S D$ )

materials may produce various volatile vapours including some gases, moisture, oils, liquids, tar and char. Hightemperature extraction of plant leaves also produces many volatile phytochemicals, which may be subject to thermal degradation or isomerization [18], known as derived phytochemicals. But many volatiles such as essential oils may easily escape into the fume without much thermal decomposition. Previous study by Havilah et al. [19] found that $L$. camara produces some volatiles during pyrolysis. High yield of azadirachtin has also been obtained by using pyrolysis of $A$. indica leaves [20].

In this study $L$. camara fume was shown to exhibit maximum toxicity with the lowest $\mathrm{LT}_{50}$ and $\mathrm{LT}_{99}$ values compared to the other volatile plant-fume tested. However, longer exposure of test insects to the less toxic phytochemical plant-fume gradually increased mortality. The highest $\mathrm{LT}_{50}$ and $\mathrm{LT}_{99}$ values were produced by $C$. zeylanicum fume followed by $A$. indica and $O$. sanctum. Extract of $L$. camara has been shown to be insecticidal against all developmental stages of storage pests and suppress their emergence from treated grains due to the presence of glycoalkaloids, lantoniside, linaroside and carminic acid [21, 22]. Previously studies of Zoubiri and Baaliouamer [9] and Mofunanya and Nta [23] have reported that leaf extract of L. camara caused $100 \%$ mortality on
Callosobruchus spp. and Sitophilus spp. within 24-96 h after treatment. The leaf oil of C. zeylanicum and Ocimum spp. has eugenol as a major component, which has high potential to act as a contact insecticide and inhibit progeny production of stored product insects [24-26]. Previous study of plant-smoke treatments of $L$. camara, $O$. sanctum and $A$. indica to control Sitophilus oryzae showed more or less similar $\mathrm{LT}_{50}$ values to the results of this study [6]. This indicates that volatile phytochemical containing plant-fume derived from the same plant species exert similar toxicity, irrespective of insect species. This may be because of release of volatile phytochemicals or formation of other toxic volatile gases during pyrolysis of plant materials. Leiner et al. [10] reported that during high-temperature pyrolysis, phytochemicals such as linalool (syntheses from isoprenoid) may form toxic thermal isomerization molecules of cis- and trans-pinan-2-ol. Selvaraj et al. [27] confirmed that the smoke of Adhatoda vasica, $A$. indica and $O$. sanctum produced by burning in hot charcoal was toxic to adult mosquitoes and also reduced mosquito activity for $6-8 \mathrm{~h}$.

It was shown that the percentage of $F_{1}$ progeny emergence in the fume treatments was significantly different from that of the controls. In the current study, lowest $F_{1}$ progeny emergence was recorded from $L$. camara and A. indica volatile phytochemical plant-fume-treated samples, but comparatively high progeny was recorded from the $C$. zeylanicum fume-treated samples. The plant-fume-treated mungbeans may hinder mating and oviposition through the mortality of weevils and/or act as oviposition deterrents on females and affect the egglaying behaviour and hatchability of laid eggs, due to the phytochemical composition of the plant material fume [23-26]. Some toxic VOCs or gases in the fume may also prevent neonatal larvae from development inside the eggs laid on the surface of mungbean seeds. Compared to the other fume treatments, C. zeylanicum and $O$. sanctum volatile fumes were less effective as oviposition deterrents or as toxicants. Apparently, this may be due to 
either steady evaporation of effective volatile chemicals into the surrounding air space after volatile fumigation treatments or weevils may simply be less susceptible to these volatile fumes. It is possible that some of the volatile phytochemicals may dissolve in $\mathrm{H}_{2} \mathrm{O}$ vapour, but according to Weidenhamer et al. [28] unsaturated solutions of monoterpenes in water vapour may also act as potent biological inhibitors.

Other than $\mathrm{CO}_{2}$ and volatile chemicals, many other gases escape during the heating similar to pyrolysis of plant materials such as $\mathrm{H}_{2} \mathrm{O}, \mathrm{CO}, \mathrm{CH}_{4}, \mathrm{H}_{2}$, etc. $[17,29]$. However, the type of gaseous form during pyrolysis is dependent on the temperature and residence time of the materials. During pyrolysis at temperatures of around $150-200{ }^{\circ} \mathrm{C}$, the probable gasses formed are volatile phytochemicals, $\mathrm{CO}_{2}, \mathrm{H}_{2} \mathrm{O}$ and/or CO. Despite differences in the plant-fume-generated samples, all four plant-fumes produced more or less similar $\mathrm{CO}_{2}$ during pyrolysis. However, some differences of $\mathrm{O}_{2}$ content in the range of $14-18 \%$ were found among the generated plant-fume samples could be due to the burning of plant materials under pyrolysis condition. Other than $\mathrm{CO}_{2}$, other gases may also derive and escapes into the test jar during heating. Therefore, resultant test insect mortality may not only depend on the VOCs, but also on the collective effect of different gases in the plant-fume. The drop of $\mathrm{O}_{2}$ content $<5 \%$ was most critical factor for the death of bruchids than rise of $\mathrm{CO}_{2}$ content in the intergranular atmosphere stored grains [2]. In this study, we did not observe very low $\mathrm{O}_{2}(>25 \%)$ and very high $\mathrm{CO}_{2}$ $(<6 \%)$ contents in the plant-fume inside the test jar. Therefore, rather than toxic gases, volatile phytochemical contained in the fume may have influenced significantly on the mortality and fecundity of $C$. chinensis. However, due to limited residence time and low pyrolysis temperature, formation of toxic gasses such as $\mathrm{CO}$ may be restricted during the heating process. Tihay and Gillard [29] found pyrolysis of 3 plant species (leaves and twigs) at the $200-600{ }^{\circ} \mathrm{C}$ produced significantly lower amounts of $\mathrm{CO}$ and $\mathrm{CH}_{4}$ than $\mathrm{CO}_{2}$ and $\mathrm{H}_{2} \mathrm{O}$. Therefore, the effect of other gases may be lower than phytochemical effect of plant-fume, but further investigations are needed to identify the active compounds of test volatile phytochemical plant-fume and other gasses.

\section{Conclusion}

Dry heat extraction similar to pyrolysis burning of plant materials and plant-fume derived from dry leaves of $L$. camara, C. zeylanicum, A. indica and O. sanctum contained toxic volatile phytochemicals. Volatile plant-fume treatment was highly lethal to $C$. chinensis and significantly reduced $F_{1}$ progeny emergence. Comparatively, highest and the lowest volatile phytochemical plant-fume was derived from the leaves of L. camara and C. zeylanicum, respectively. Therefore, plant materials-derived phytochemical containing plant-fume can be used as an alternative but traditional technique to grain fumigation. However, further research is needed to find out the active compounds of the volatile phytochemical in plant-fume and to develop an appropriate fumigation technology.

\begin{abstract}
Abbreviations
$\mathrm{RH}$ : Relative humidity (\%); Pl\%: Progeny emergence inhibition percentage; $N_{T}$ : Number of insects in treatment; $N_{c}$ : Number of insects in control sample; $Y$ : Insect mortality (\%); $t$ : Exposure time (h); $q$ : Lowest efficiency of mortality; $b$ : Model constant of curve transition; $c$ : Slope factor of the curves; $L_{50}$ : Lethal time for 50\%; $\mathrm{LT}_{99}$ : Lethal time of 99\%; ANOVA: Analysis of variance; SD: Standard deviation; SE: Standard error; LSD: Fisher's least significant difference test; $P$ : Probability \%; $r_{\text {adj }}^{2}$ Adjusted regression coefficient; F: F-statistics; FSE: Fit standard error; Cl: $95 \%$ confidence interval.
\end{abstract}

\section{Acknowledgements}

I am very grateful to early technical assistant of Mr. A. Peries and Mr. C. Nawaratne from former Rice Processing Research and Development Centre, Anuradahapura, Sri Lanka, and Mr. K.A.K.L. Chandrasiri form Department of Food Science and Technology who gave me the fullest support during this study

\section{Authors' contributions}

The author has contributed in the conceptualization and designing of the experiment, statistical analysis and manuscript preparation. All technical assistants support to carry out the laboratory studies. The author read and approved the final manuscript.

\section{Funding}

No research funding received.

\section{Availability of data and materials}

All available data are shown in the figures and tables.

Ethics approval and consent to participate

Not applicable.

Consent for publication

The author give their personal consent for publication.

Competing interests

The author declares that he has no competing interests.

Received: 5 April 2020 Accepted: 11 June 2020

Published online: 27 October 2020

\section{References}

1. Adikarinayake TB, Palipane KB, Müller J. Quality changes and mass loss of paddy during airtight storage in a ferro-cement bin in Sri Lanka. J Stored Prod Res. 2006;42:377-90.

2. Prasantha BDR, Prasadi VPN,Wimalasiri KMS. Effect of hermetic storage on end-use quality of mungbean, In: Arthur FH, Kengkanpanich R, Chayaprasert W, Suthisut D, editors. Proceedings of the 11 th International working conference on stored product protection, Chiang Mai, Thailand; 2014. p. 373-84.

3. Kawuki RS, Agona A, Nampala P, Adipala E. A comparison of effectiveness of plant-based and synthetic insecticides in the field management of pod and storage pests of cowpea. Crop Protect. 2005;24:473-8.

4. Appleby JH, Credland PF. Environmental conditions affect the response of west African Callosobruchus maculatus (Coleoptera: Bruchidae) 
populations to susceptible and resistant cowpeas. J Stored Prod Res. 2004;40:269-87.

5. Donahaye EJ. Current status of non-residual control methods against stored product pests. Crop Protect. 2000;19:571-6.

6. Prasantha BDR. Efficacy of burnt plant material smoke for protection of stored paddy against infestation of Sitophilus oryzae (L.). In: Adler C, Navarro S, Schöller M, Stengard-Hanse L, editors. Proceedings of the meeting integrated protection in stored products, IOBC-WPRS Bulletin 25; 2002. P. 171-176.

7. Rajendranand S, Sriranjini V. Plant products as fumigants for stored-product insect control. J Stored Prod Res. 2008:44:126-35.

8. Abdelghany AY, Awadalla SS, Abdel-Baky NF, El-Syrafi HA, Field PG. Storedproduct insects in botanical warehouses. J Stored Prod Res. 2010:46:93-7.

9. Zoubiri S, Baaliouamer A. Chemical composition and insecticidal properties of Lantana camara L. leaf essential oils from Algeria. J Essent Oil Res. 2012:24:377-83

10. Leiner JA, Stolle A, Ondruschka B, Netscher T, Bonrath W. Thermal behavior of pinan-2-ol and linalool. Molecules. 2013;18:8358-75.

11. Prasantha BDR, Reichmuth $\mathrm{CH}$, Adler C. Lethality and kinetic of diatomaceous earth uptake by the bean weevil (Acanthoscelides obtectus [Say] Coleoptera: Bruchinae): Influence of short-term exposure period. J Stored Prod Res. 2019. https://doi.org/10.1016/j.jspr.2019.101509.

12. Nyamador SW, Mondedji AD, Kasseney BD, Ketoh GK, Koumaglo HEK, Glitho IA. Insecticidal activity of four essential oils on the survival and oviposition of two sympatric bruchid species: Callosobruchus maculatus F. and Callosobruchus subinnotatus PIC (Coleoptera: Chrysomelidea: Bruchinae). J Stored Prod Postharv Res. 2017:8:103-12.

13. Wang ZY, Lu YJ, Zhao YR. Fumigation action of four plant oils against eggs of Callosobruchus chinensis (L.) (Coleoptera: Bruchidae). Jo Essent Oil Bear Plants. 2016;19:1394-403.

14. Boeke SJ, Van Loon JJA, Van Huis A, Kossou DK, Dickle M. The use of plant materials to protect stored leguminous seeds against seed beetles: a review. Wageningen University Papers 2001-2003, The Netherlands, Backhuys Publishers; 2001

15. Soon-li K, Jung-Yeon R, Do-Hyoung K, Han-Seung L, Young-Joon A. Insecticidal activities of aromatic plant extracts and essential oils against Sitophilus oryzae and Callosobruchus chinensis. J Stored Prod Res. 2003:39:293-303.

16. Sharkey TD, Yeh S. Isoprene emission from plants. Annu Rev Plant Physiol Plant Mol Biol. 2001;52:407-36.

17. Ramchandra PP. Understanding the product distribution from biomass fast pyrolysis. Dissertations, lowa State University, Digital repository paper $11767 ; 2010$.
18. Ohtani H, Tsuge S. Degradation mechanisms of condensation polymers. In: Wampler PT, editor. Applied Pyrolysis Handbook. USA: Marcel Dekker; 1995. p. 97-105.

19. Havilah PH, Sharma PK, Gopina THM. Combustion characteristics and kinetic parameter estimation of Lantana camara by thermogravimetric analysis. Biofuels. 2016;1:1-8.

20. Ley SV, Anderson JC, Blaney WM, Lidert Z, Morgan ED, Robinson NG, Simmond MSJ. Chemistry of insect antifeedants from Azadirachta indica (Part-3): reactions on the c-22-23 enol ether double bond of azadirachtin and conversion to 22, 23-dihydro-23-beta-methoxazadirachtin. Tetrahed Lett. 1988;29:5433-6.

21. Gotyal BS, Srivastava C, Walia S, Jain SK, Reddy DS. Efficacy of wild sage (Lantana camara) extracts against almond moth (Cadra cautella) in stored wheat (Triticum aestivum) seeds. Ind J Agric Sci. 2010;80:433-6.

22. Saxena RC, Dixit OP, Harshan V. Insecticidal action of Lantana camara against Callosobruchus chinensis (Coleoptera: Bruchidae). J Stored Prod Res. 1992;28:279-81.

23. Mofunanya AAJ, Nta Al. Entomotoxicity of six indigenous plants extracts in controlling Callosobrochus maculatus (Fabricius) (Coleoptera: Chrysomelidae) infestation in stored Vigna unguiculata L. Walp. IOSR J Pharm Biol Sci. 2016;11:45-9.

24. Ratnesakera D, Nayanthara KHG. Efficacy of cinnamon and citronella oil vapours in the control of Callosobruchus chinensis L. in bulk stored green gram. J Food Agric. 2013;3:1-6.

25. Jayaprakasha GK, Rao LJM. Chemistry, biogenesis, and biological activities of Cinnamomum zeylanicum. Crit Rev Food Sci Nutr. 2011;51:547-62.

26. Obeng-Ofori D, Reichmuth Ch. Bioactivity of eugenol, a major component of essential oil of Ocimum suave (Wild.) against four species of stored-product coleopteran. Int J Pest Manag. 2010;43:89-94.

27. Selvaraj PR, Manoharan AC, Pandian RS. Herbal smoke a potential repellent and adulticide for mosquitoes. Insect Environment. 1995:1:14-5.

28. Weidenhamer JD, Macias FA, Fischer NH, Williamson GB. Just how insoluble are monoterpenes? J Chem Ecol. 1993;19:1799-807.

29. Tihay V, Gillard P. Pyrolysis gases released during the thermal decomposition of three mediterranean species. J Anal Appl Pyrol. 2010;88:168-74.

\section{Publisher's Note}

Springer Nature remains neutral with regard to jurisdictional claims in published maps and institutional affiliations.

\section{Submit your manuscript to a SpringerOpen ${ }^{\circ}$ journal and benefit from:}

- Convenient online submission

- Rigorous peer review

- Open access: articles freely available online

- High visibility within the field

Retaining the copyright to your article

Submit your next manuscript at springeropen.com 